\title{
Review
}

Special articles: Asian Conference on Biomass Science

特集 : アジアバイオマス科学会議

\section{Lignin Extraction from Lignocellulosic Biomass Using Sub- and Supercritical Fluid Technology as Precursor for Carbon Fiber Production}

\author{
Khalidatul Athirah KHALID, Asimi Ana AHMAD, and Tau Len-Kelly YONG ${ }^{\dagger}$
}

(Received November 15, 2016)

\begin{abstract}
Recent technologies in the production of chemicals and bio-materials products are focusing on lignocellulosic resources since it is the world' s most abundant material, low cost, as well as sustainable. Lignocellulosic biomass consists of three main compounds: cellulose, hemicellulose, and lignin. Productions of carbon fiber from lignin as its precursor are proposed to reduce the usage of fossil fuel based materials. However, the difficulties on recovering lignin from biomass are widely known. Therefore, several studies were conducted to explore possible technologies to isolate lignin from the complex lignocellulosic biomass in simple and minimal cost. One of the potential technologies is by using sub- and supercritical fluids. The polymer made of from phenylpropane units ( $p$-coumaryl alcohol, coniferyl alcohol and sinapyl alcohol), the building block of lignin in plants can be converted to low molecular weight compounds using sub- and supercritical fluid technology with diverse applications including carbon fiber production. Hence, this paper aims to review on the lignin extraction from lignocellulosic biomass using sub- and supercritical fluid technology as precursor for carbon fiber production.
\end{abstract}

\section{Key Words}

Carbon fiber, Lignin, Biomass

\section{Introduction}

Carbon fiber is a high performance materials used in the production of advanced composite materials. Carbon fiber is often described as fiber composed of at least $92 \%$ of carbon by weight obtained through pyrolysis process. Currently, the manufacturing of carbon fiber is dominated by polyacrylonitrile (PAN) precursor due to the mixture of tensile and compressive properties as well as the yield of carbon produced ${ }^{1)}$, followed by pitch, both from petroleum and coal resources.

The usage of materials from fossil fuels gives significant disadvantages, as this source are finite and gives irreparably damage to the environment. Besides, carbon fibers produced from PAN and pitch are expensive due to the multiple stages as well as complex procedures involved during the manufacturing process. These resulted in limitation of carbon fiber applications in industry to only

Universiti Kuala Lumpur, Malaysian Institute of Chemical and Bioengineering Technology (UniKL MICET)

Melaka, Malaysia

$\uparrow$ Corresponding author: kytlen@unikl.edu.my specialty products such as aerospace, high-end automotive, sporting goods and special industrial applications ${ }^{2)}{ }^{3)}$. Therefore, efforts in finding alternative precursors, which are sustainable and economical is aggressively done.

Lignocellulosic biomass comprises of three important natural polymer compounds; cellulose, hemicellulose, and lignin. Table 1 shows the composition of cellulose, hemicellulose, and lignin in different types of wood. These compounds can be used to produce several bio-based chemicals and materials.

Lignin is the second most abundant organic material after cellulose ${ }^{7)}{ }^{8}$. It is a complex, amorphous, and cyclic natural polymer composed of phenylpropane units ( $p$-coumaryl alcohol, coniferyl alcohol and sinapyl alcohol) as the predominant building blocks that are randomly crosslinked by dissimilar chemical bond. The compositions of these phenylpropane units may differ according to the types of plants. For example, about 90\% of coniferyl alcohol is found in lignin softwood. Meanwhile, $p$-coumaryl alcohol is mainly present in grass lignin, while sinapyl alcohol is found in hardwood lignin ${ }^{9}$. As a phenolic polymer, lignin can 
Table 1 Cellulose, hemicellulose, and lignin content in different types of lignocellulosic biomass ${ }^{4) ~} 6$ )

\begin{tabular}{lccc}
\hline $\begin{array}{l}\text { Types of ligno-cellulosic } \\
\text { biomass }\end{array}$ & $\begin{array}{c}\text { Cellulose } \\
(\%)\end{array}$ & $\begin{array}{c}\text { Hemi-cellulose } \\
(\%)\end{array}$ & $\begin{array}{c}\text { Lignin } \\
(\%)\end{array}$ \\
\hline Hardwood stems & $40-55$ & $24-40$ & $18-25$ \\
Softwood stems & $40-50$ & $25-35$ & $25-35$ \\
Nut shells & $25-30$ & $25-30$ & $30-40$ \\
Corn cobs & 45 & 35 & 15 \\
Grasses & $25-40$ & $35-50$ & $10-30$ \\
Paper & $85-99$ & 0 & $0-15$ \\
Wheat Straw & 30 & 50 & 15 \\
Sorted refuse & 60 & 20 & 20 \\
Leaves & $15-20$ & $80-85$ & 0 \\
Cotton seed hairs & $80-95$ & $5-20$ & 0 \\
Newspaper & $40-55$ & $25-40$ & $18-30$ \\
Waste papers from & $60-70$ & $10-20$ & $5-10$ \\
chemical pulp & & & $20-29$ \\
Primary waste water solid & $8-15$ & - & $2.7-5.7$ \\
Solid Cattle manure & $1.6-4.7$ & $1.4-3.3$ & 6.4 \\
Coastal Bermuda grass & 25 & 35.7 & 12 \\
Switchgrass & 45 & 31.4 & - \\
Swine waste & 6.0 & 28 &
\end{tabular}

be used as an alternative to replace petroleum-based raw materials and can be applied in the production of phenolic resin, adhesives, as well as precursor for carbon fiber ${ }^{10)}$. However, lignin is linked via inter unit linkages making its chemical structure very complicated and almost impossible to isolate simply by organic solvents ${ }^{11)}$. In addition, the treatment condition may modify the chemical structure and subsequently reduce the lignin's quality for further application. Therefore, proper isolation method is required to minimise the modification of lignin structure during its depolymerisation from the lignocellulosic biomass.

\section{Carbon Fibers from Lignin}

The earliest technology of carbon fiber derived from lignin was patented by Otani et al. (1969) ${ }^{12}$. The lignin was isolated from woody materials (softwood, hardwood, and vegetation), which subsequently underwent melt spinning and dry spinning processes to produce carbon fiber, graphite fiber, and activated carbon. Fiber of about 20-30 $\mu \mathrm{m}$ was successfully produced from hardwood Kraft lignin through one pot melt-spinning method at the rate of $5-10 \mathrm{~m} / \mathrm{min}$ with tensile strength of $784.53 \mathrm{MPa}$. In another early study (1970s) targeted for commercialisation of lignin carbon fiber (Kayacarbon) in a small-scale production by Nippon Kayaku, they utilized alkali-pulped softwood lignin and hardwood lignin mixtures with the ratio of 1:1. They successfully produced fiber with tensile strength of 686.47 MPa. Although this early technologies has shown its potential, the emergence of alternative precursor material, Polyacrylonitrile (PAN), hampered its progression. PAN produced fibers, which were more briskly and offered better tensile strength, forcing these technologies to cease.

Sudo and Shimizu (1992) ${ }^{10)}$ extracted lignin as carbon fiber precursor through steam-explosion process. This process required the woody materials to be pressurised under high-pressure steam followed by explosive decompression with organic or alkali solvent. The extracted lignin subsequently underwent hydrogenolysis and spinning process. The fibers had properties of 7.6-10.3 $\mu \mathrm{m}$ in diameters, 660-890 $\mathrm{MPa}$ tensile strength, and 40.7$47 \mathrm{GPa}$ modulus of elasticity. Although this technology has successfully produced carbon fibers with comparable properties, the 2 -steps process hampered its progress especially towards big scale commercialization.

Kubo et al. (1998) ${ }^{13)}$ attempted to isolate lignin from softwood using atmospheric acetic acid pulping. Acetic acid functioned to eliminate the infusible high molecular mass fraction in the raw materials therefore removing the volatile materials from the lignin. Fibers produced from this technology did not have to undergo thermo stabilisation process. This lead to the reduction of production cost and simultaneously increased the tensile strength by reducing its diameter. The carbon fiber formed displayed properties comparable to other lignin-based carbon fibers from phenolated exploded lignin. The method used less severe condition, as acetic acid is an organic acid.

Meanwhile, Kadla et al. $(2002)^{14)}$ reported their study on lignin-based carbon fiber manufactured from three different types of lignin; hardwood Kraft lignin, organosolv lignin and blends of lignin with poly (ethylene oxide) (PEO). The process involved the lignin purification/desaltation with distilled water. HCL was subsequently added to maintain the $\mathrm{pH}$ below 5 until the salt content reduced to 1,000ppm. The precursor was extruded at $130-240^{\circ} \mathrm{C}$ and stabilized at $250^{\circ} \mathrm{C}$. The fibers were subsequently carbonized in nitrogen at $1000^{\circ} \mathrm{C}$. This process yielded fibers with 40-46\% carbon with tensile strength and modulus in the range of 400-550 $\mathrm{MPa}$ and 30-60 GPa respectively. The technology exhibited by this study was more versatile and able to tailor to the different natures of lignin. However, the usage of inorganic acid may cause complications of its isolation from the produced carbon fiber.

\section{Conventional Lignin Refining Process}

There are numerous lignin conversion technologies based on extraction/isolation process in order to utilise lignin for other applications. Lignin is usually obtained as by-products in the paper pulping process as well as in the production of cellulosic ethanol for fuel. One of the common lignin refining process widely used today is Kraft pulping ${ }^{3)}$. 
Kraft pulping is a process of separating cellulose from hemicellulose and lignin in high temperature by treating the woody materials with white liquor comprising of an aqueous solution of sodium hydroxide and sodium sulphide. Through this process, lignin and a large portion of hemicellulose were obtained in the form of black liquor, which subsequently undergo delignification process to separate lignin-hemicellulose complex through precipitating process. Lignin in solid phase is then washed with acidic solution and dried ${ }^{15}$.

Another conventional method of lignin isolation is organosolv process. In this process, the lignin-cellulose networks are segregated using mixtures of organic solvent and water. Common solvents used are acetic acid and ethanol. The process is carried out at high temperature and pressure where lignin is isolated through acid precipitation. The advantages of organosolv lignin over Kraft lignin are less modification on the lignin structure and no sulphur produced from the reaction ${ }^{16)}$

Steam exploded lignin is another conventional process widely used by bio- refinery to extract lignin from lignocellulosic biomass. Woody biomass is treated with steam at high temperature $\left(180-200{ }^{\circ} \mathrm{C}\right)$ and pressure followed by sudden decompression with acid, resulting in partial hydrolysis process. Under this condition, the linkages between cellulose, hemicellulose, and lignin will rupture and subsequently water-insoluble lignin with low level of carbohydrate and wood-extractive impurities are produced ${ }^{16)}$.

These conventional lignin-refining processes had several disadvantages. For example, the use of sodium hydroxide and sodium sulphide in the Kraft lignin causes the presence of inorganic contaminants especially sulfur, which is hazardous in the form of thiols when covalently bonded to lignin ${ }^{17)}$. Meanwhile, the use of acid catalyst in steam-exploded process will increase not only the production cost, but also the equipment cost as highly corrosive materials is used in the reaction.

The use of strong inorganic alkali/acid as catalyst caused significant modification to the polymer structure in lignocellulosic biomass especially lignin which may diminish its quality for further applications. Besides, the presence of strong alkali/acid will complicate the subsequent lignin purification process ${ }^{18}$. Therefore, other alternative process to isolate lignin is needed in order to produce a better quality lignin from lignocellulosic biomass such as sub- and supercritical fluid technology.

\section{Sub- and Supercritical Fluid Technology}

Recently, focus has been given to the extraction process using sub- and supercritical fluid technology. Theoretically, fluid is defined as supercritical fluid under supercritical conditions when its pressure and temperature exceed its critical values. Meanwhile, fluid is said to be under subcritical condition when its temperature or pressure is below its critical point.

Sub- and supercritical fluids have tremendous potential for lignin extraction/isolation from plant biomass especially as precursor for carbon fiber production due to its reliability and rapid reaction. Under sub- and supercritical conditions, the properties of the fluid e.g. density, diffusivity, dielectric constant, and viscosity can be controlled and manipulated according to the reaction needs through process parameters such as temperature and pressure ${ }^{19}$. The increase in temperature resulted in lower dielectric constant. At low dielectric constant, the fluid behaves similarly to non-polar organic substance; therefore it can break and dissolve the complex linkages between cellulose, hemicellulose and lignin in plant biomass. Through adjustment of the fluid properties via temperature and pressure, the treatment may specifically targeted in isolating lignin only from the complex matrix of plant biomass.

There are numerous types of sub- and supercritical fluids; e.g. water, $\mathrm{CO}_{2}$, phenol etc. For instance, water under subcritical conditions may improve the extraction efficiency through enhancement of the mass transfer and changes in its polarity without the present of catalyst. High ionic product of water could be obtained under subcritical condition, accelerating acid or base-catalysed reaction such as hydrolysis in the biomass. Meanwhile, water under supercritical condition is a thermally stable solvent that does not require the presence of catalyst ${ }^{20)}$. The absence of catalyst during the reaction may reduce the cost for lignin extraction process.

Another potential sub- and supercritical fluid is $\mathrm{CO}_{2}$. $\mathrm{CO}_{2}$ offers clean and safe extraction process since it is nonflammable, non-toxic, and its removal from the end product is relatively simple ${ }^{19}$. $\mathrm{CO}_{2}$ when in contact with heat at high pressure may give superior solvating power of liquid and diffusivity of gas ${ }^{21}$. Besides, its critical condition is relatively low $\left(31.1^{\circ} \mathrm{C}\right.$ and $\left.7.38 \mathrm{MPa}\right)$. Therefore, sub- and supercritical $\mathrm{CO}_{2}$ can be excellent reaction media for extraction of various compounds including lignin from plant biomass under milder condition.

Study by Yong and Matsumura (2012) ${ }^{22)}$ found that rapid conversion of lignin and its complete depolymerisation process occurred within $5 \mathrm{~s}$ of residence time under supercritical water condition. The study also concluded that the formation of phenolic compounds occurred in short residence times. This is because the ether bonds in lignin are easily degraded under supercritical condition. 
The utilisation of lignin as precursor for carbon fiber has been extensively studied ${ }^{10)}{ }^{12)} \sim 14$ ). Hence, this paper will review on the extraction of lignin from different types of biomass using sub- and supercritical technology with the potential as precursor for the production of carbon fiber. The review will focus on the effects of several process parameters towards the reaction such as temperature, reaction time, and types of fluids used.

\section{Previous study of lignin extraction from biomass using sub- and supercritical technology.}

Several studies reported the feasibility of suband supercritical technology for lignin extraction. It was concluded that the efficiency of the method is highly dependent on the reaction conditions. Bludworth and Knopf (1993) ${ }^{23)}$ used supercritical ammonia-water mixtures to extract lignin from yellow poplar wood. The initial study using ammonia produced very small yield with minimal selectivity of delignification. They concluded that ammonia only reacted with some portion of lignin and carbohydrates in the wood. However, the bulk wood remains relatively unaffected. Therefore, the study extended by using $20 \% / 80 \%$ water/ammonia under the same temperature and pressure. The result showed significant reduction in the lignin content of the wood from $20.6 \%$ to $14.6 \%$. Based on this finding, it can be concluded that water functioned as cosolvent in the solubilisation of the reaction products as well as to induce favourable changes in the pore structure of the wood. Temperature also affected the lignin extraction. There is a decrease of residual lignin content in the wood with increasing temperature. Thus, it can be said that high temperature under critical conditions improved the lignin extraction from plant biomass. This is in agreement with Mishra and Saka (2011) ${ }^{18)}$.

Mishra and Saka (2011) ${ }^{18)}$ studied the kinetic behaviour of liquefaction of Japanese beech in subcritical phenol at $160-350{ }^{\circ} \mathrm{C}, 3-30 \mathrm{~min}$, and 0.9-4.2 $\mathrm{MPa}$. This study suggested two different kinetics mechanism based on two different temperature range. At low temperature range of $160-290^{\circ} \mathrm{C}$, higher liquefaction rate constant for lignin was obtained. However, not all lignin are liquefied. About $1.0 \mathrm{wt} . \%$ of lignin insoluble residue in the Japanese beech wood was obtained after $30 \mathrm{~min}$. At $350^{\circ} \mathrm{C}$ and $30 \mathrm{~min}$, almost 100\% liquefaction of lignin were obtained. They further concluded that there are two types of linkages present in the lignin, non-condensed ether linkages and condensed carbon-carbon (C-C) linkages. Ether linkages are usually breakable at lower temperature range. Meanwhile, the cleavage of carbon-carbon linkages that has resistance against liquefaction in lower temperature range would probably take place at high temperature. These show the significance of high temperature and pressure towards the reaction.

Another study conducted by Machmudah et al. (2015) ${ }^{24)}$ extracted lignin using hot compressed water in a flowthrough reactor. Lignin was extracted from Japanese rice straw under different reaction temperature $\left(170-230^{\circ} \mathrm{C}\right)$ and flowrate $(1.42-4.67 \mathrm{~mL} / \mathrm{min})$ with constant pressure and reaction time of $4 \mathrm{MPa}$ and $60 \mathrm{~min}$, respectively. Subcritical water caused hydrolysis reaction and cleavage of bonds between heteroatoms and carbon atoms during the reaction process. Based on this study, wt\% of lignin recovery increased with temperature and flowrate. The maximum lignin removal from Japanese rice straw (85\%) occurred at $170^{\circ} \mathrm{C}$ and $200^{\circ} \mathrm{C}$ with flow rates of $4.67 \mathrm{~mL} / \mathrm{min}$. Higher flowrate allowed the dissolved lignin to be removed from the reactor before it reacted with other substances or precipitate, which improved the lignin recovery. This indicated the rapidness of the reaction under subcritical conditions. However, at $230^{\circ} \mathrm{C}$ under the same condition, the recovery of lignin decreased to $64 \%$. The decrease in lignin recovery at high temperature is due to the cleavage of ether and C-C linkages. The hydrothermal degradation of these linkages produced several phenols and methoxy phenols through the hydrolysis process ${ }^{25)}$.

Based on studies by Mishra and Saka (2011) ${ }^{18)}$ and Machmudah et al. (2015) ${ }^{24)}$, it was found that there are discrepancies regarding the effect of temperature towards the reaction. Mishara and Saka (2011) ${ }^{18)}$ discovered that high temperature increased the liquefaction rate of lignin due to the cleavage of ether and C-C linkages present in lignin. Meanwhile, Machmudah et al. (2015) ${ }^{24)}$ observed at $230^{\circ} \mathrm{C}$, the recovery of lignin decreased due to the broken linkages of ether and C-C linkages. The different results from these studies can be attributed to the different kind of solvent used in the reaction.

Seisu et al. (2003) ${ }^{26)}$ proposed two different reaction mechanisms for extraction of lignin from biomass in supercritical water-phenol mixture. The first mechanism occurred without the presence of phenol. Meanwhile, the second mechanism occurred with the presence of phenol as co-solvent. In the reaction using supercritical water without phenol, they suggested two different reactions during the depolymerisation of lignin; dealkylation and hydrolysis that yielded formaldehyde and low molecular weight fragments with reactive functional groups as well as compounds such as phenol, syringols, guaiacols, and catechols. These formaldehyde and low molecular weight fragment then underwent crosslinking that subsequently produced higher- molecularweight fragment of the residual lignin known as char. The 
formation of char during the reaction process may reduce the efficiency of lignin extraction during the reaction process. The study then proceeded with the presence of phenol as co-solvent and found that no char formation from the reaction. The non-formation of char during the reaction was attributed to the entrapment of active fragment (for example formaldehyde) with active sites by excess phenol. Phenol has the ability to function as capping agent that prevented the repolymerization of decomposed lignin fragment with other compound during the reaction process. This is similar with the findings by Wahyudiono et al. (2008) ${ }^{27)}$. This study shows the significance of the difference types of sub- and supercritical fluids towards the reaction when it is used alone or as mixtures.

Ko et al. (2014) ${ }^{28)}$ studied the effect of liquid hot water to isolate lignin from mixed hardwood chips at $180-210^{\circ} \mathrm{C}$, and 5-15 min. Based on this study, it was shown that the \% of lignin recovery increased with temperature from $86.5 \%$ to $90.1 \%$ due to the condensation reaction of lignin with other degradation products. Longer reaction time increased the content of acid insoluble lignin and decreased the acid soluble lignin. This indicated that lignin underwent chemical composition or structure changes during the reaction process. This is similar with Samuel et al. (2010) ${ }^{29}$.

\section{Future Development of Lignin Extraction using Sub- and Supercritical Fluid Technology.}

There are several complications in the extraction of lignin from lignocellulosic biomass using sub- and supercritical fluid technology that needed to be addressed. Among these challenges is the efficiency of the extraction technology, quality of lignin produced as well as the difficulties in understanding the reaction mechanism while undergoing depolymerisation to monomers under sub- and supercritical conditions. All these challenges hinder the advancement of the technology to produce lignin-based carbon fiber commercially.

The lignin yield from extraction/isolation using suband supercritical water are still low compared to other catalytic extraction processes such as hydropyrolysis ${ }^{30}$. The potential to improve the lignin extraction yield can be achieved through addition of co-solvent such as phenol, butanol, or boric acid. The addition of co-solvent may be able to improve the depolymerisation of lignin and subsequently increase the selectivity of the desired product ${ }^{26)} 30$ ) 31). However, studies are still limited and comprehensive experimental work is needed to determine its feasibility.

In addition, the purity of lignin produced must adhere to the quality needed for it to be suitably used as carbon fiber precursor material. The feasibility of lignin as carbon fiber precursor is also influenced by the nature of the plant biomass used. Since lignocellulosic biomass has different lignin constituents, therefore an improved understanding of these differences towards the extraction/isolation process is also crucial.

Several studies has demonstrated the feasibility of obtaining lignin from lignocellulosic biomass using sub and supercritical fluid technology 18) 23) 24). However, very few studies discussed the reaction mechanism and pathway of lignin isolation/extraction using sub- and supercritical fluids. Different types of lignocellulosic biomass as well as suband supercritical fluids will produce different structure as well as the yield itself. Therefore, the study of the reaction mechanism is essential in order to elucidate the formation and degradation of the intermediate compounds under sub- and supercritical reaction as this may give better understanding on behaviour of lignin with this method.

\section{Conclusion}

Sub- and supercritical fluid technology has the potential as effective method for lignin extraction as carbon fiber precursor. The efficiency of lignin extraction/isolation from plant biomass is highly dependent on the several process parameters as well as other additional solvent and medium of reaction. It can be concluded that although the sub- and supercritical technology has shown its potential for lignin extraction/isolation, its future improvement, especially to produce lignin as carbon fiber precursor, is crucial in order to produce better quality of precursor material as well as to improve its feasibility.

\section{References}

1) Bahl, O. P.; Shen, Z.; Lavin, J. G.; Ross, R. A., Manufacture of Carbon Fibers, in Donnet, J-B.; Wang, T., K.; Peng, J., C., M.; Rebouillat, S. (Eds.), Carbon Fibres, Third Edition, Revised and Expended, New York: Marcel Dekker, pp. 1-94 (1998)

2) Baker, D. A.; Rials, T. G., Journal of Applied Polymer Science, 130(2), 713-728 (2013)

3) Huang, X., Materials, 2(4), 2369-2403 (2009)

4) Harmsen, P.; Huijgen, W.; López, L.; Bakker, R., Food and Biobased Research, 1-49 (2010)

5) Jørgensen, H.; Kristensen, J. B.; Felby, C., Biofuels, Bioprod. \& Bioref, 119-134 (2007)

6) Sun, Y.; Cheng, J., Bioresource Technology, 83, 1-11 (2002)

7) Min, D. Y.; Smith, S. W.; Chang, H. M.; Jameel, H., BioResources, 8(2), 1790-1800 (2013)

8) Hu, L.; Pan, H.; Zhou, Y.; Zhang, M., Bio Resources, 6(3), 3515-3525 (2011)

9) Luo, J., Lignin Based Carbon Fibre. Master thesis, 
University of Maine, Maine, United State, (2010), http:// www.if.ufrrj.br/

10) Sudo, K.; Shimizu, K., Journal of Applied Polymer Science, 44, 127-134 (1992)

11) Nonaka, H.; Funaoka, M., Biomass and Bioenergy, 35(4), 1607-1611 (2011)

12) Otani, S.; Kiryu-shi, Fukuoka, Y.; Igarshi, B.; Sasaki, K.; Takasaki-shi, U.S Patent No. 3,461,082. United States: U.S Patent and Trademark Office, (1969)

13) Kubo, S.; Uraki, Y.; Sano, Y., Carbon, 36(7-8), 1119-1124 (1998)

14) Kadla, J. F.; Kubo, S.; Venditti, R. A.; Gilbert, R. D.; Compere, A. L.; Griffith, W., Carbon, 40(15), 2913-2920 (2002)

15) Ramasubramanian, G., Influence of Lignin modification on PAN-Lignin copolymers as potential carbon fiber precursors. Master thesis, Iowa State University, Ames, Iowa, (2013), http://lib.dr.iastate.edu.

16) Calvo-Flores, F. G.; Dobado, J. A., ChemSusChem, 3(11), 1227-1235 (2010)

17) Graglia, M.; Kanna, N.; Esposito, D., ChemBioEng, (6), 377-392 (2015)

18) Mishra, G.; Saka, S., Bioresource Technology, 102(23), 10946-10950 (2011)

19) Abbas, K. A.; Mohamed, A.; Abdulamir, A. S.; Abas, H. A., American Journal of Biochemistry and Biotechnology, 4(4), 345-353 (2008)

20) Wahyudiono; Sasaki, M.; Goto, M., Decomposition of lignin alkaline and chemicals recovery in sub- and supercritical water, 2(1), 1-6 (2013)

21) Neata, G.; Campeanu, G.; Popescu, M. I.; Popa, O.; Babeanu, N.; Basaraba, A.; Popescu, D. D., Romanian Biotechnological Letters, 20(3), 10406-10412 (2015)

22) Yong, T. L.; Matsumura, Y., Ind. Eng. Chem. Res., 51, 11975-11988 (2012)

23) Bludworth, J.; Carl Knopf, F., The Journal of Supercritical Fluids, 6(4), 249-254 (1993)

24) Machmudah, S.; Wahyudiono, Kanda, H.; Sasaki, M.; Goto, M., Engineering Journal, 19(4), (2015)

25) Toor, S. S.; Rosendahl, L.; Rudolf, A., Energy, 36(5), 23282342 (2011)

26) Saisu, M.; Sato, T.; Watanabe, M.; Adschiri, T.; Arai, K., Energy \& Fuels, (17), 922-928 (2003)

27) Wahyudiono, Sasaki, M.; Goto, M., Chemical Engineering and Processing: Process Intensification, 47(9-10), 1609-1619 (2008)

28) Ko, J. K.; Kim, Y.; Ximenes, E.; Ladisch, M. R., Biotechnology and Bioengineering, 112(2), 252-262 (2015)

29) Samuel, R.; Pu, Y.; Raman, B.; Ragauskas, A. J., Applied Biochemistry and Biotechnology, 162(1), $62-74$ (2010)

30) Davis, K. M.; Rover, M.; Brown, R. C.; Bai, X.; Wen, Z.; Jarboe, L. R., Energies, 9(808), 1-28 (2016)

31) Matsumura, Y.; Sasaki, M.; Okuda, K.; Takami, S.; Ohara, S.; Umetsu, M.; Adschiri, T., Combustion Science and Technology, 178(1-3), 509-536 (2006) 